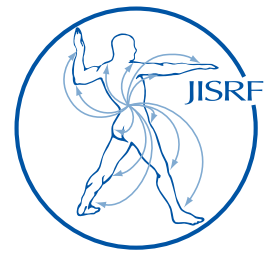

Check for updates

\title{
New Instrumentation Reduces Operative Time in Medial Unicompartmental Knee Arthroplasty Using the Oxford Mobile Bearing Design
}

\author{
Berend $K^{1}$, Hurst $\mathrm{J}^{1}$, Morris $\mathrm{M}^{1}$, Adams $\mathrm{J}^{1}$, Lombardi $A^{1}$
}

\begin{abstract}
Redesigned instrumentation has become available for implantation of the Oxford Mobile Bearing Medial unicompartmental knee arthroplasty. To assess the benefit of these changes, we compared operative time of 200 Phase III and 176 Microplasty UKA done 2008-2011. An average time savings of 8.6 minutes was seen with the Microplasty design. Additionally, the standard deviation in operative times, minimum and maximum operatives were lower in knees in which Microplasty instrumentation was utilized. A $15 \%$ savings in operative time was seen with the new Microplasty instrumentation.
\end{abstract}

Keywords: unicompartmental knee arthroplasty, surgical technique, instrumentation, mobile-bearing, operative time Level of Evidence: AAOS Therapeutic Level III - Retrospective comparative therapeutic study

\section{Introduction}

Multiple publications cite excellent results in terms of survivorship and functional outcomes with a medial-mobile bearing unicompartmental partial knee arthroplasty design utilizing the Phase III minimally invasive instrumentation platform (Zimmer Biomet, Warsaw, IN) (Figure 1A-D) [1-13]. The most recent modifications to the mobile-bearing Oxford Partial Knee Arthroplasty (Zimmer Biomet) were intended to enhance the stability and mechanics of the femoral component and improve the process of implantation and reproducibility of implant positioning. Previous reports have demonstrated good early outcomes and more accurate and reproducible femoral component alignment and implantation using this newer design and improved instrumentation $[14,15]$. Specific design changes to the instrumentation platform include siz- ing spoon-stylus system to decrease the need to recut the tibial plateau (Figure 2A-B), an intramedullary based femoral alignment guide (Figure 3A-B) and an accurate and efficient guide for reducing impingement (Figure 4A-B) (Microplasty Instrumentation; Zimmer Biomet). In addition to improved accuracy, the Microplasty instrumenta-

\footnotetext{
1 Keith R. Berend, MD; Jason M. Hurst, MD; Michael J. Morris, MD; Joanne B. Adams, BFA; Adolph V. Lombardi, Jr., MD Joint Implant Surgeons, Inc., 7277 Smith's Mill Road, Suite 200, New Albany, Ohio 43054 USA

(Direct reprint requests to Keith R. Berend)
}

(C) 2015 Berend, Hurst, Morris, Adams, Lombardi. All rights reserved Authors retain copyright and grant the journal right of first publication with the work Reconstructive Review follows the Creative Commons Attribution-NonCommercial CC BY-NC. This license allows anyone to download works, build upon the material, and share them with others for non-commercial purposes as long as they credit the senior author, Reconstructive Review, and the Joint Implant Surgery \& Research Foundation (JISRF). An example credit would be: "Courtesy of (senior author's name), Reconstructive Review, JISRF, Chagrin Falls, Ohio". 


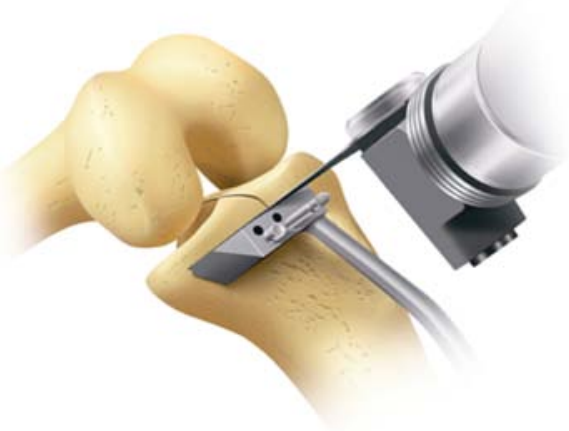

Figure 1A.

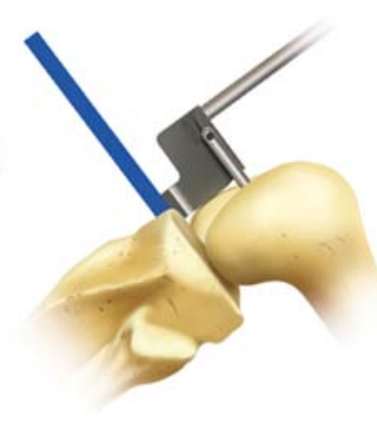

Figure $1 B$.

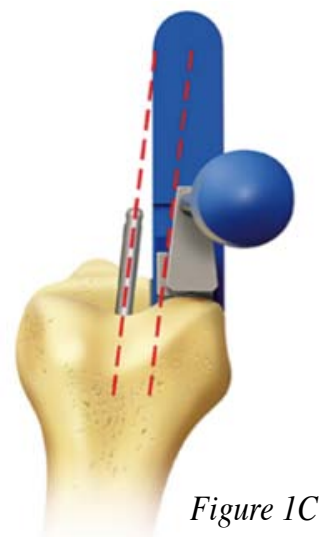

Figure $1 C$.

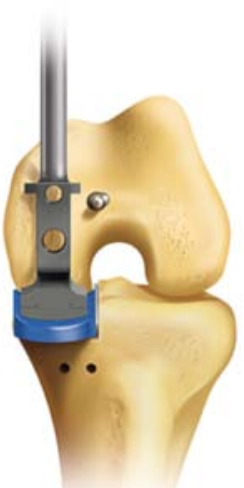

Figure 1D.

Figure 1. The Phase III instrumentation: Tibial resection (1A), femoral alignment lateral view $(1 B)$, femoral alignment $A / P$ view (1C), femoral alignment distal femoral view (1D) (Reproduced courtesy of Zimmer Biomet, Inc.)

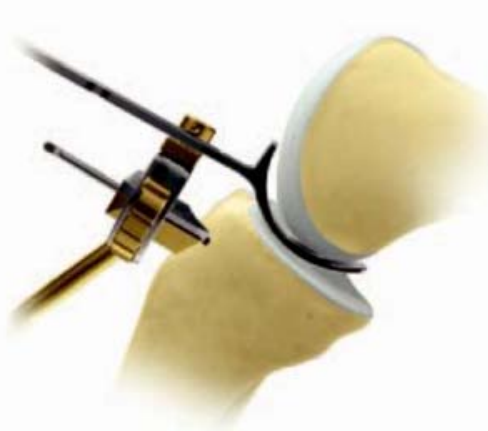

Figure 2A.

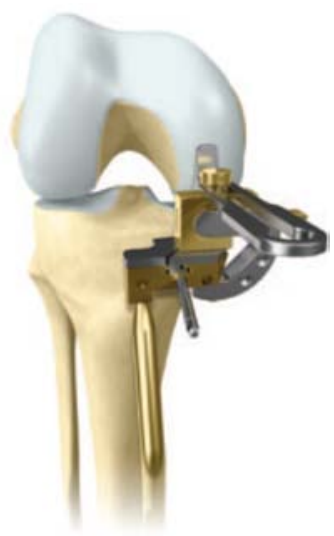

Figure $2 B$.

Figure 2. Microplasty instrumentation tibial resection guide with spoon/stylus and "G-clamp" for setting resection depth: lateral view (2A), A/P view (2B). (Reproduced courtesy of Zimmer Biomet, Inc.)

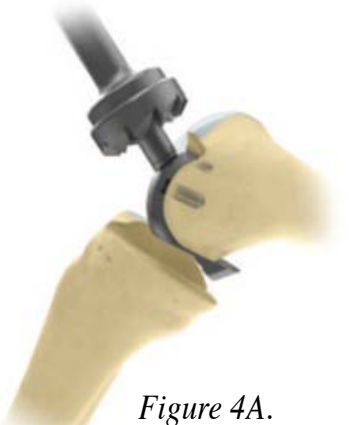

Figure 4A.

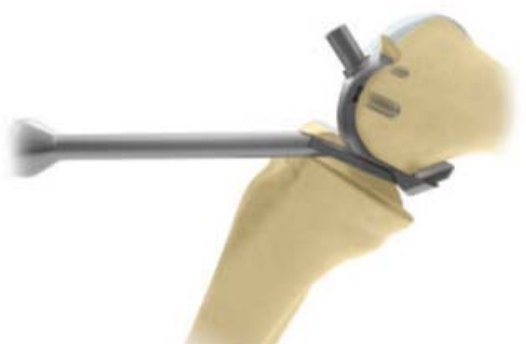

Figure $4 B$.
Figure 4 Microplasty impingement removal device: Removal of anterior impingement (4A), removal of posterior impingement $(4 B)$. (Reproduced courtesy of Zimmer Biomet, Inc.)

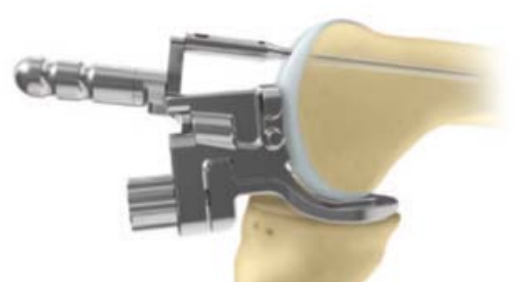

Figure $3 A$.

Microplasty intramedullary linked femoral alignment guide: lateral view (3A), A/P view $(3 B)$. (Reproduced courtesy of Zimmer Biomet, Inc.)

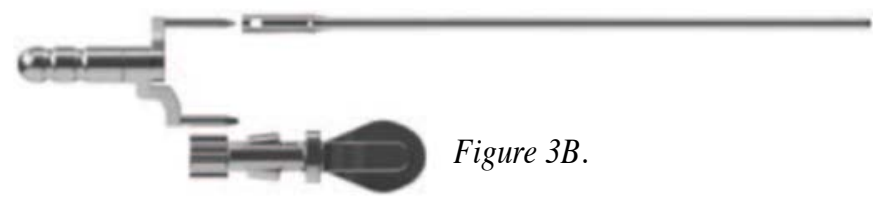

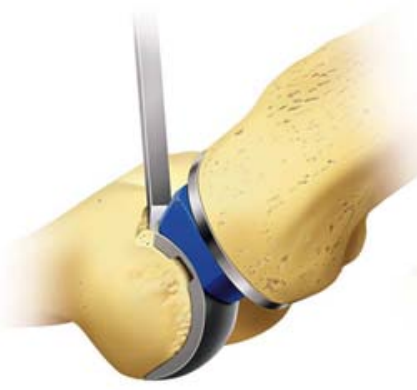

Figure 5A.

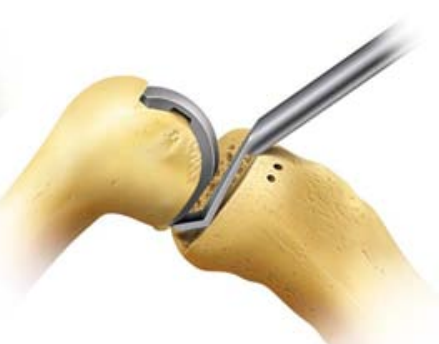

Figure 5B.
Figure 5. For the Phase III instrumentation, anterior osteopnytes ana potential impinging bone were removed with the use of an osteotome: Removal of anterior impingement (5A), removal of posterior impingement (5B). (Reproduced courtesy of Zimmer Biomet, Inc.) 
tion platform was intended to streamline the surgical procedure making it more efficient. The purpose of this study is to determine if the new Microplasty instrumentation allows for a more efficient surgical procedure that would translate into reduced operative time.

\section{Materials and Methods}

A query of our practice's arthroplasty registry revealed 176 knees in patients who signed an institutional review board-approved general research consent allowing retrospective review, and underwent medial unicompartmental knee arthroplasty (UKA) performed with the Microplasty instrumentation between July 2011 and December 2011. A matched group of 200 UKA in patients who signed an IRBapproved general research consent allowing retrospective review, implanted using the Phase III instrumentation and the single-peg femoral component from 2008 to 2011, was selected. Only procedures in which unilateral UKA were performed were examined; 38 simultaneous bilateral procedures were excluded (Table 1). The surgeons (KRB, AVL, JMH, MJM) begin using the Phase III instrumentation in July of 2004, and thus the Phase III group represents procedures that are well beyond the initial learning curve.

The preoperative diagnosis was avascular necrosis in 1 knee (enhanced twin-peg group) and osteoarthritis in all others. The groups were well matched in terms of gender, age, body mass index, preoperative ROM, and Knee Society pain and clinical scores. Forty-six percent of patients were males and 54\% were females. Mean patient age at surgery was 63.7 years overall (stdev 9.1; range 29-88 years), mean BMI was $32.3 \mathrm{~kg} / \mathrm{m}^{2}$ (stdev 6.6 , range $17-57$ $\mathrm{kg} / \mathrm{m}^{2}$ ), and mean ROM was $116.3^{\circ}$ (stdev 7.7, range $90^{\circ}$ $135^{\circ}$ ).

Operative time was recorded for each procedure. Operative time was defined as the time from initial incision until the final dressing was applied. Operative time between the Microplasty group and the Phase III group was compared using the Satterthwaite method and the Folded F test. Statistical significance was defined as $\mathrm{p}<0.05$.

\section{Results}

The mean operative time was significantly shorter with the Microplasty instrumentation (49 minutes) compared with the Phase III (58 minutes). This difference was significant ( $\mathrm{t}$ value 5.23; $\mathrm{p}<0.0001$ and $\mathrm{F}$ value $1.41 ; \mathrm{p}=0.02$ ). Additionally, the standard deviation was significantly lower in the Microplasty group (14 minutes) versus the Phase III (17 minutes). The minimum and maximum operative times were also less in the Microplasty group compared with the Phase III (24-88 minutes versus 30-126 minutes).

Table 1. Demographics and results

\begin{tabular}{|c|c|c|c|}
\hline Characteristic & Phase III Instrumentation & Microplasty Instrumentation & P value \\
\hline Knees & 200 & 176 & \\
\hline Patients & 177 & 164 & \\
\hline \multicolumn{4}{|l|}{ Gender by patients } \\
\hline Male patients & $76(43 \%)$ & $81(49 \%)$ & 0.322 \\
\hline Female patients & $101(57 \%)$ & $83(51 \%)$ & \\
\hline \multicolumn{4}{|l|}{ Gender by knees } \\
\hline Knees in male patients & $84(42 \%)$ & $86(49 \%)$ & 0.182 \\
\hline Knees in female patients & $116(58 \%)$ & $90(51 \%)$ & \\
\hline Mean age (years) & $62.9( \pm 9.6,29-88)$ & $64.5( \pm 8.5,44-81)$ & 0.086 \\
\hline Mean height (inches) & $66.7( \pm 4.0,59-76)$ & $66.8( \pm 4.0,59-75)$ & 0.759 \\
\hline Mean weight (pounds) & $202.0( \pm 42.0,120-330)$ & $207.6( \pm 47.0,116-375)$ & 0.227 \\
\hline Mean body mass index $(\mathrm{kg} / \mathrm{m} 2)$ & $31.9( \pm 6.0,17-52)$ & $32.7( \pm 7.3,17-57)$ & 0.235 \\
\hline Mean preoperative range of motion (degrees) & $116.5( \pm 7.8,90-135)$ & $116.1( \pm 7.6,90-130)$ & 0.640 \\
\hline Mean preoperative Knee Society pain score (0-50 possible) & $9.8( \pm 11.8,0-50)$ & $9.5( \pm 10.6,0-45)$ & 0.834 \\
\hline Mean preoperative Knee Society clinical score (0-100 possible) & $41.0( \pm 14.1,18-83)$ & $40.4( \pm 12.7,23-94)$ & 0.637 \\
\hline Mean operative time (minutes) & $58.0( \pm 17.1,30-126)$ & $49.4( \pm 14.4,24-88)$ & $<0.001$ \\
\hline
\end{tabular}




\section{Discussion}

Unicompartmental knee arthroplasty (UKA) using the Oxford Phase III medial mobile-bearing knee has enjoyed excellent results [1-13]. Price and Svard reported 91.0\% all cause cumulative survival rate at 20 years in a series of 543 patients (682 knees) [12]. Our center previously reported $95.2 \%$ survival at a mean of 3.7 years in 688 patients with 839 medial Oxford III UKA [1]. We have also previously reported that use of the new Microplasty instrumentation results in more accurate and reproducible femoral component placement [15]. White et al reported $100 \%$ survival and $97 \%$ patient satisfaction at 2 years postoperative utilizing the Microplasty instrumentation and twinpeg femoral design [14]. An additional goal of the new instrumentation was to allow for a more efficient procedure. The current study demonstrates that this new instrumentation platform reduces operative time.

Specifically, the three steps of the procedure in which we believe this improved efficiency and decreased operative time are gained include the tibial resection, femoral alignment, and removal of impingement. The spoon-based Microplasty instrumentation (Figure 2) references the posterior femoral condyle and acts as a stylus to accurately remove 6.5 (3 "G-clamp") or 7.5mm (4 "G-clamp) of tibial resection. This accuracy reduces the number of time the tibial plateau requires re-resection. Further, in our previous study, we noted that this bone-conserving approach to tibial preparation resulted in a greater number of thinner 3 and $4 \mathrm{~mm}$ bearings utilized in the Microplasty group [15]. This provides the added benefit of not only less operative time, but a more conservative tibial resection and less bone removal.

With Phase III instrumentation, femoral alignment required visualization and adjustment of 6 separate variables or alignment measurements (Figure 1A-D). This individual adjustment required checking each alignment position while manually holding the other 5 positions. With the intramedullary alignment guide, not only is the alignment more accurate and reproducible, but this step requires less operative time (Figure 3A-B). With Phase III instrumentation, anterior osteophytes and potential impinging bone were removed with the use of an osteotome (Figure 5AB). This was inaccurate and frequently required checking the bearing in extension multiple times to ensure an appropriate amount of bone was removed. The Microplasty guide for removing impingement (Figure 4A-B) allows for this step to be performed once with no need to recheck impingement-free range of motion, thus reducing operative time. These efficiencies resulted in an average of almost 9 minutes less operative time or a $15 \%$ reduction.
Microplasty instrumentation decreases operative time for implanting the Oxford mobile-bearing medial unicompartmental knee. A $15 \%$ reduction in operative time could translate into the ability to perform more surgeries, decreased risk of infection, and decreased length of tourniquet use, all of which would have positive benefits to surgeon and patient.

\section{Disclosure Statement}

One or more of our authors have disclosed information that may present potential for conflict of interest with this work. For full disclosures refer to last page of this journal.

\section{References}

1. Bergeson AG, Berend KR, Lombardi AV Jr, Hurst JM, Morris MJ, Sneller MA Medial mobile bearing unicompartmental knee arthroplasty: early survivorship and analysis of failures in 1000 consecutive cases. J Arthroplasty. 2013;28(9 Suppl):172-5. [PubMed] [CrossRef]

2. Bitsch RG, Keudell AV, Losina E, Fitz W. Good accuracy of the Phase III Oxford mobile bearing unicompartmental knee instrumentation. Acta Orthop 2013;84(4):406-9. [PubMed] [CrossRef]

3. Emerson RH Jr, Higgins LL. Unicompartmental knee arthroplasty with the Oxford prosthesis in patients with medial compartment arthritis. J Bone Joint Surg Am. 2008;90(1):118-22. [PubMed] [CrossRef]

4. Faour-Martín O, Valverde-García JA, Martín-Ferrero MA, Vega-Castrillo A, de la Red Gallego MA, Suárez de Puga CC, Amigo-Liñares L. Oxford Phase 3 unicondylar knee arthroplasty through a minimally invasive approach: long-term results. Int Orthop. 2013;37(5):833-8. [PubMed] [CrossRef]

5. Kristensen PW, Holm HA, Varnum C. Up to 10-year follow-up of the Oxford medial partial knee arthroplasty -695 cases from a single institution. J Arthroplasty. 2013;28(9 Suppl):195-8. [PubMed] [CrossRef]

6. Lim HC, Bae JH, Song SH, Kim SJ. Oxford phase 3 unicompartmental knee replacement in Korean patients. J Bone Joint Surg Br. 2012;94(8):1071-6. [PubMed] [CrossRef]

7. Lisowski LA, van den Bekerom MP, Pilot P, van Dijk CN, Lisowski AE. Oxford Phase 3 unicompartmental knee arthroplasty: medium-term results of a minimally invasive surgical procedure. Knee Surg Sports Traumatol Arthrosc. 2011;19(2):277-84. [PubMed] [CrossRef]

8. Matharu G, Robb C, Baloch K, Pynsent P. The Oxford medial unicompartmental knee replacement: survival and the effect of age and gender. Knee. 2012;19(6):9137. [PubMed] [CrossRef]

9. Murray DW, Pandit H, Weston-Simons JS, Jenkins C, Gill HS, Lombardi AV, et al Does body mass index affect the outcome of unicompartmental knee replacement? Knee. 2013;20(6):461-5. [PubMed] [CrossRef]

10. Pandit H, Jenkins C, Gill HS, Barker K, Dodd CA, Murray DW. Minimally invasive Oxford phase 3 unicompartmental knee replacement: results of 1000 cases. J Bone Joint Surg Br. 2011;93(2):198-204. [PubMed] [CrossRef]

11. Pietschmann MF, Wohlleb L, Weber P, Schmidutz F, Ficklscherer A, Gülecyüz MF, Safi E, Niethammer TR, Jansson V, Müller PE. Sports activities after medial unicompartmental knee arthroplasty Oxford III-what can we expect? Int Orthop. 2013;37(1):31-7. [PubMed] [CrossRef]

12. Price AJ, Svard U. A second decade lifetable survival analysis of the Oxford unicompartmental knee arthroplasty. Clin Orthop Relat Res. 2011;469(1):174-9. [PubMed] [CrossRef]

13. Yoshida K, Tada M, Yoshida H, Takei S, Fukuoka S, Nakamura H. Oxford Phase 3 unicompartmental knee arthroplasty in Japan - clinical results in greater than one thousand cases over ten years. J Arthroplasty. 2013;28(9 Suppl):168-171. [PubMed] [CrossRef]

14. White SH, Roberts S, Jones PW. The twin peg Oxford partial knee replacement: the first 100 cases. Knee. 2012;19(1):36-40. [PubMed] [CrossRef]

15. Hurst JA, Berend KR, Adams JB, Lombardi AV Jr. Radiographic comparison of mobile-bearing partial knee single-peg versus twin-peg design. J Arthroplasty 2015; 30(3): 475-8. [PubMed] [CrossRef] 